\title{
Author/Title Index to volume 9 (1989)
}

(Numbers appearing within parentheses before the page numbers indicate the issue in which an item was published.)

Bell, K.C., LANDSEARCH: better access to Commonwealth land and geographic information

Bjerregaard, E.T.D., Experiences from an IM project in three Danish industrial companies

Buchan, R.L., Intertwining thesauri and dictionaries

(4) $225-233$

(3) $171-175$

Cawkell, A.E., Editorial: Hypermedia

$(1 / 2) 115-116$

Cawkell, A.E., Editorial: The risks of ignoring information

(6) 325

Cederberg, B., Changes in information strategies in a company-Experiences from ASEA

Chadwyck-Healey, Sir Charles, MundoCart and Supermap; cartographic and statistical data-bases on CD-ROM

Clark, J.E., NTIS: a key partner in unlocking the world's technology

Clough, R., ASSASSIN: the ongoing development of a text storage and retrieval system

(4) $241-245$

(3) 139-147

(5) 289-294

(3) $149-160$

Edem, U.S., Serials acquisition and management in Nigerian Academic Libraries: implications for quality library services

Elias, A.W., Copyright, licensing agreements and gateways

(3) $161-170$

(6) $347-361$

Elias, A.W., Editorial: MEETINGS \& meetings...

(5) 257

Farkas-Conn, I.S., Information as a corporate resource

(4) 205-215

Hämäläinen, P., Enhanced benefits from business information services: JOTI-An executive information system

Hamrefors, S., Business intelligence systems as a route to improving competitive positions

(4) 191-196

Harrap, C.: see M.G. McPherson

Hodge, G.M. and A.M. Stefany, B-I-T-S: producton of a customized floppy disk product

(4) $217-224$

$(1 / 2) 101-106$

(5) $259-269$

Jackson, K.M.: see W.R. Kinyon

(5) $279-288$

Jarvis, J.R., Developing an expert system using a PC-based shell

$(1 / 2) \quad 67-77$

Kalseth, K., Editorial

(4) 189

Karivalo, M., Training for information management in a company

(6) $341-346$

0167-5265/90/\$03.50 @ 1990 - Elsevier Science Publishers B.V. 
Kinyon, W.R. and K.M. Jackson, Look before you leap: avoiding marketing problems through producer/user collaboration

(5) $279-288$

Krebs, R., The role of information and documentation in the automobile industry

Krull, J.S., The role of the service bureau in multimedia diversification

(4) $235-240$

(5) $271-277$

Lee, E.S.: see J.N. MacGregor

(3) $127-137$

Leonard, P.G. and P.A. Spender, Contractual \& intellectual property protection of databases

$(1 / 2) \quad 33-43$

Lim, E.H.-T., Networking activities in Southeast Asia

$(1 / 2) \quad 15-32$

Lowry, G.R., Editorial: The Australasian information services industry in 1989

$(1 / 2) \quad 1-2$

Lyons, K. and P. Sharma, Opportunities and obstacles in land information systems (1/2) 57- 65

MacGregor, J.N., E.S. Lee and T. Whalen, The feature matching approach to the computer retrieval of graphics: an enhancement

(3) $127-137$

McPherson, M.G., C. Harrap and J.E. O'Reilly, Enhancing search results by editing, analysis and packaging

$(1 / 2) 101-106$

O’Reilly, J.E.: see M.G. McPherson

$(1 / 2) 101-106$

Pearsall, J., STATUS/IQ: a semi-intelligent information retrieval system

(5) 295-309

Quinn, S., Australian and New Zealand databases in 1988

$(1 / 2) \quad 3-14$

Sharma, P.: see K. Lyons

$(1 / 2) \quad 57-65$

Sharp, G.E., Business information services and implications for Australian Corporate Libraries

(3) $117-126$

Smith, I.W., Towards an evaluation of CD-ROM products in the library user services environment

$(1 / 2) \quad 85-91$

Spender, P.A.: see P.G. Leonard

$(1 / 2) 33-43$

Stefany, A.M.: see G.M. Hodge

(5) $259-269$

Thompson, S.S., From documentation service centre to documentation competence centre; Experiences from Norsk Hydro

(4) $247-253$

Unruh, B., Copyright issues: the primary/secondary journal interface

(6) $363-371$

Ventress, A., Networks and CD-ROMs

$(1 / 2) \quad 93-100$

Warren, D., Supporting CD-ROM in an academic library

Wormell, I., Strategic information management to improve competitiveness

(1/2) $79-84$

(4) 197-204 